\title{
Myoglobin to Creatinine Ratio Measurement
}

National Cancer Institute

\section{Source}

National Cancer Institute. Myoglobin to Creatinine Ratio Measurement. NCI Thesaurus.

Code C106546.

The determination of the ratio of myog lobin compared to creatinine present in a sample.

The measurement may be expressed as a ratio or percentage. 